\title{
Main Physical Features, Echocardiographic and Renal Ultrasonographic Findings of Turner Syndrome in 107 Pediatric Patients
}

\author{
Akçahan Akalın ${ }^{a} \quad$ İlker Ertuğrul ${ }^{b}$ Pelin Özlem Şimşek-Kiper ${ }^{a} \quad$ Gülen Eda Utine ${ }^{a}$ \\ Koray Boduroğlu ${ }^{a}$ \\ aDepartment of Pediatric Genetics, Department of Pediatrics, Hacettepe University Faculty of Medicine, Ankara, Turkey; \\ ${ }^{b}$ Department of Pediatric Cardiology, Department of Pediatrics, Hacettepe University Faculty of Medicine, Ankara, Turkey
}

\section{Keywords \\ Turner syndrome $\cdot$ Congenital heart defects · Kidney diseases · Chromosomal aneuploidy}

\begin{abstract}
Turner syndrome (TS) is one of the most common malformation syndromes in females. A total number of 107 TS patients, diagnosed between 2000 and 2018, were evaluated for their phenotypic features, and cardiac and renal findings. The mean age of patients at admission was $10.08 \pm 4.9$ years (range, newborn to 18 years). Four different karyotype groups were encountered, and the most common findings in all groups were short stature, followed by cubitus valgus. Echocardiographic findings of 85 patients were available among which 63 ( $n=63 / 85,74.1 \%$ ) were found to be normal. The most common cardiac anomaly was left ventricular outflow tract/aortic arch pathology detected in 9 patients ( $n=$ 9/22, 40.9\%). Renal malformations were detected in 15 patients ( $n=15 / 84,17.9 \%$ ) by renal ultrasonography, and horseshoe kidney was the most common renal malformation, followed by left multicystic dysplastic kidney. There was no significant difference in the frequency of renal malformation and cardiac anomalies among the 4different karyotype groups ( $x^{2}$ exact test, $p>0.05$ ). Compared with the literature, the frequency of renal anomalies was detected at a lower
\end{abstract}

karger@karger.com

(C) 2021 S. Karger AG, Basel

www.karger.com/msy

Karger! rate. Karyotype analysis should be carried out in all female patients with short stature, even if there are no associated phenotypic findings suggestive of TS. Since cardiac anomalies are frequently seen in TS patients and they represent a common cause of mortality, echocardiography should be carried out as soon as the definite diagnosis is established. Renal anomalies may be less frequent than cardiac anomalies; however, evaluation of TS patients with renal ultrasonography should be done at the time of diagnosis. Although renal ultrasonography can be used as the initial renal screening in TS patients, it may underestimate the frequency of renal malformation; hence, further management may be required.

(c) 2021 S. Karger AG, Basel

\section{Introduction}

Turner syndrome (TS) results from the partial or complete loss of the second $\mathrm{X}$ chromosome in phenotypic females and has a prevalence of 1 in 2,000 to 2,500 live-born female children [Shankar and Backeljauw, 2018]. TS features were first described by Henry Turner in 1938, and pathogenicity of X chromosome monosomy was identified in 1959 [Ford et al., 1959]. Monosomy 45 is present in approximately $45 \%$ of the cases, while the rest of the patients

Correspondence to:

Akçahan Akalın, akcahanbalci@gmail.com 
have various structural abnormalities [Wolff et al., 2010]. The 2 most common features seen in $90 \%$ of patients with TS are short stature and early ovarian failure [Bondy et al., 2009]. Other well-known characteristics of the condition consist of some dysmorphic features, including webbing of the neck, low posterior hairline, broad chest, cubitus valgus, shortening of fourth metacarpals, nail dysplasia, and facial features including ptosis and low-set or malrotated ears; however, these features are now reported in fewer than half of the affected individuals [Bondy et al., 2009]. Short stature, pubertal delay/ovarian insufficiency, cardiac and renal abnormalities, sensorineural hearing loss, ophthalmologic problems, thyroid abnormalities, metabolic syndrome, inflammatory bowel disease, and neurocognitive issues are all recognized to be relatively common in TS. Congenital cardiovascular defects are found in approximately $50 \%$ of the affected individuals, and these anomalies increase the risk of aortic dissection, the most important life-threatening health problem faced by TS patients [Bondy et al., 2009]. Renal anomalies are also common in TS and have been reported as high as $60 \%$ in older series. In more recent series, the prevalence varies between 33 and $60 \%$ [Lippe et al., 1988]. In this study, we aimed to investigate the frequencies of cardiac and renal malformations, as well as the frequencies of some well-recognized dysmorphic features, in a cohort of 107 TS patients.

\section{Materials and Methods}

Main phenotypic features of TS, and echocardiography and renal ultrasonography findings were retrospectively analyzed in pediatric patients diagnosed by chromosome analysis between January 2000 and January 2018 at the Hacettepe University Faculty of Medicine, Department of Pediatric Genetics. The medical data of the patients were gathered from the hospital archive records. Echocardiography results were classified into 7 groups: left ventricular outflow tract/aortic arch pathologies, mitral valve anomalies, endocardial cushion defect, conotruncal anomaly, patent ductus arteriosus (PDA), ventricular septal defect (VSD), and atrial septal defect (ASD). Cytogenetic results were divided in 4 groups; monosomy X, mosaic karyotype, $\mathrm{X}$ chromosome structural abnormality (including isochromosome of the long arm, ring, or translocation), and karyotypes that include the entire Y chromosome or its fragments. Main phenotypic findings of TS that were evaluated included webbing of the neck, low posterior hairline, widely spaced nipples, cubitus valgus, and short metacarpals. Age, height, and major complaints of the patients on admission were also recorded. Statistical analyses were performed using SPSS for Windows Version 22.0. Numerical variables were summarized by mean \pm standard deviation and qualitative variables were summarized by number and percentage. $\chi^{2}$ test was used to compare the frequency of renal malformations and cardiac anomalies in 4 different karyotype groups. $p<0.05$ was considered statistically significant.

\section{Results}

Retrospective data were available from a total of 107 pediatric patients with cytogenetically proven TS in a 17-year period for evaluation of phenotypic features, echocardiographic and renal ultrasonographic findings. The mean age at the time of the first evaluation was $10.08 \pm 4.9$ years (range, newborn to 18 years). When the patients were divided into 4 groups according to their karyotypes, the most common finding in all groups was short stature (85\%), followed by cubitus valgus (54.2\%) and metacarpal shortness (48.5\%) (Table 1). Karyotype analysis revealed 45,X in 45 (42.1\%) patients, mosaic karyotype in $11(10.3 \%)$ patients, $\mathrm{X}$ structural abnormality (isochromosome of the long arm, ring chromosomes, derivative chromosomes formed by segmental deletions or duplications, and translocations) in 47 (43.9\%) patients, and a karyotype that included the entire Y chromosome or its fragments in $4(3.7 \%)$ patients (Table 2). The most common complaint on admission was short stature (60.7\%) which was followed by short stature with primary amenorrhea (18.7\%) and postnatal findings (hand and foot lymphedema, 11.2\%). Other complaints were prenatal findings $(3.7 \%)$, premature ovarian insufficiency (2.8\%), and trigonocephaly (1.9\%) (Table 3). Of all patients, $82.2 \%$ were under the 3 rd centile, $5.6 \%$ were between $3 \mathrm{rd}$ and 10 th centiles, and $3.7 \%$ of the patients were at or above the 25 th centile (Table 3 ).

Echocardiographic findings of 85 patients were available, and 63 (74.1\%) were found to be normal. Cardiac findings were classified as left ventricular outflow tract/ aortic arch pathologies, mitral valve anomalies, conotruncal anomalies, endocardial cushion defects, VSD, and ASD (Table 1). The most common cardiac finding was left ventricular outflow tract/aortic arch pathology detected in $9(8.4 \%)$ patients, mitral valve anomaly in 4 (3.7\%) patients, ASD in $3(2.8 \%)$ patients, conotruncal anomaly in $1(0.9 \%)$ patient, endocardial cushion defect in $1(0.9 \%)$ patient, and VSD in $1(0.9 \%)$ patient. Two patients had an acquired heart valve disorder (aortic insufficiency). One patient was deceased because of pulmonary hypertension and Eisenmenger syndrome due to untreated PDA.

Renal ultrasonography was performed in 84 patients. Renal anomaly was observed in only 15 (17.9\%) individuals (Table 1). The most common renal anomaly was horseshoe kidney and was detected in 8 (7.4\%) patients. Right renal agenesis, bifid pelvis, axis abnormalities, crossed renal ectopia, and left multicystic dysplastic kidney were other renal abnormalities encountered. The prevalence of renal and cardiac anomalies in the present 
Table 1. Phenotypic, cardiac, and renal findings compared to karyotype structure

\begin{tabular}{|c|c|c|c|c|c|}
\hline & $\begin{array}{l}\text { Monosomy X } \\
(42 \%) \\
(n=45)\end{array}$ & $\begin{array}{l}\text { Mosaic } \\
\text { karyotype } \\
(10.2 \%) \\
(n=11)\end{array}$ & $\begin{array}{l}\text { X structural } \\
\text { abnormality } \\
(43.9 \%) \\
(n=47)\end{array}$ & $\begin{array}{l}\text { Y chromosome } \\
\text { fragments } \\
(3.7 \%) \\
(n=4)\end{array}$ & $\begin{array}{l}\text { All patients } \\
(n=107)\end{array}$ \\
\hline \multicolumn{6}{|l|}{ Phenotypic findings } \\
\hline Short stature $(\leq 3 \mathrm{p})$ & $7 / 45(82.2 \%)$ & $8(72.7 \%)$ & $42(89.3 \%)$ & $4(100 \%)$ & $91 / 107(85 \%)$ \\
\hline Short metacarpal bones & $25 / 45(55.5 \%)$ & $4(36.3 \%)$ & $21(44.6 \%)$ & $2(50 \%)$ & $52 / 107(48.5 \%)$ \\
\hline Low posterior hairline & $21 / 45(46.6 \%)$ & $5(45.4 \%)$ & $15(31.9 \%)$ & $1(25 \%)$ & $42 / 107(39.2 \%)$ \\
\hline Widely spaced nipples & $19 / 45(42.2 \%)$ & $3(27.7 \%)$ & $16(34 \%)$ & $2(50 \%)$ & $40 / 107(37.3 \%)$ \\
\hline \multicolumn{6}{|l|}{ Cardiac findings } \\
\hline Normal & $29 / 45(64.4 \%)$ & $5 / 11(45.4 \%)$ & $25 / 47(53.1 \%)$ & $4 / 4(100 \%)$ & $63 / 85(74.1 \%)$ \\
\hline Abnormal & $9 / 45(20.2 \%)$ & $3 / 11(27.2 \%)$ & $10 / 47(21.2 \%)$ & - & $22 / 85(25.8 \%)$ \\
\hline Aortic coarctation & $1 / 45$ & - & $1 / 47$ & - & $2 / 107(1.8 \%)$ \\
\hline \multicolumn{6}{|l|}{ Mitral valve anomalies } \\
\hline Mitral stenosis & - & - & $1 / 47$ & - & $1 / 107(0.9 \%)$ \\
\hline Mitral valve prolapse & $1 / 45$ & - & $2 / 47$ & & $3 / 107(2.8 \%)$ \\
\hline Atrial septal defect & $2 / 45$ & - & $1 / 47$ & - & $3 / 107(2.8 \%)$ \\
\hline Acquired cardiac problems (aortic insufficiency) & $2 / 45$ & - & $1 / 47$ & - & $3 / 107(2.8 \%)$ \\
\hline \multicolumn{6}{|l|}{ Conotruncal anomaly } \\
\hline Tetralogy of Fallot & - & - & $1 / 47$ & - & $1 / 107(0.9 \%)$ \\
\hline Endocardial cushion defect & - & - & $1 / 47$ & - & $1 / 107(0.9 \%)$ \\
\hline Ventricular septal defect & - & - & $1 / 47$ & - & $1 / 107(0.9 \%)$ \\
\hline No data available & $8 / 45$ & $3 / 11$ & $11 / 47$ & - & $22 / 107(20.6 \%)$ \\
\hline Crossed renal ectopia & - & $1 / 11$ & - & - & $1 / 107(0.9 \%)$ \\
\hline Horseshoe kidney/hydronephrosis & $1 / 45$ & - & - & - & $1 / 107(0.9 \%)$ \\
\hline No data available & $9 / 45$ & $2 / 11$ & $12 / 47$ & - & $23 / 107(21.5 \%)$ \\
\hline
\end{tabular}

study was 17.9 and $25.8 \%$, respectively. There was no significant difference in the frequency of renal malformation and cardiac anomalies among the 4 different karyotype groups ( $\chi^{2}$ test, $\left.p>0.05\right)$.

\section{Discussion}

TS occurs due to complete or partial missing of the $\mathrm{X}$ chromosome in females. This is the only monosomy syndrome that humans can survive. The disease incidence is approximately 1 in 2,500 live-borns. The initial description by Henry Turner in 1938 was based on the triad of infantilism, webbing of the neck, and deformity of the elbow (cubitus valgus) [Turner, 1938]; however, short stature, ovarian failure, cardiac and renal abnormalities, sensorineural hearing loss, ophthalmic problems, thyroid disease, metabolic syndrome, inflammatory bowel disease, and neurocognitive issues are also common in TS [Shankar and Backeljauw, 2018]. This study was performed to determine the most common clinical features of TS patients diagnosed during the last 20 years in our 
Table 2. Chromosomal classification of Turner syndrome

\begin{tabular}{|c|c|c|c|}
\hline Classification & Karyotype & $N=107$ & $100 \%$ \\
\hline $\begin{array}{l}\text { X chromosome structural } \\
\text { abnormality (isochromosome } \\
\text { of the long arm, ring chromosome } \\
\text { or translocation) }\end{array}$ & 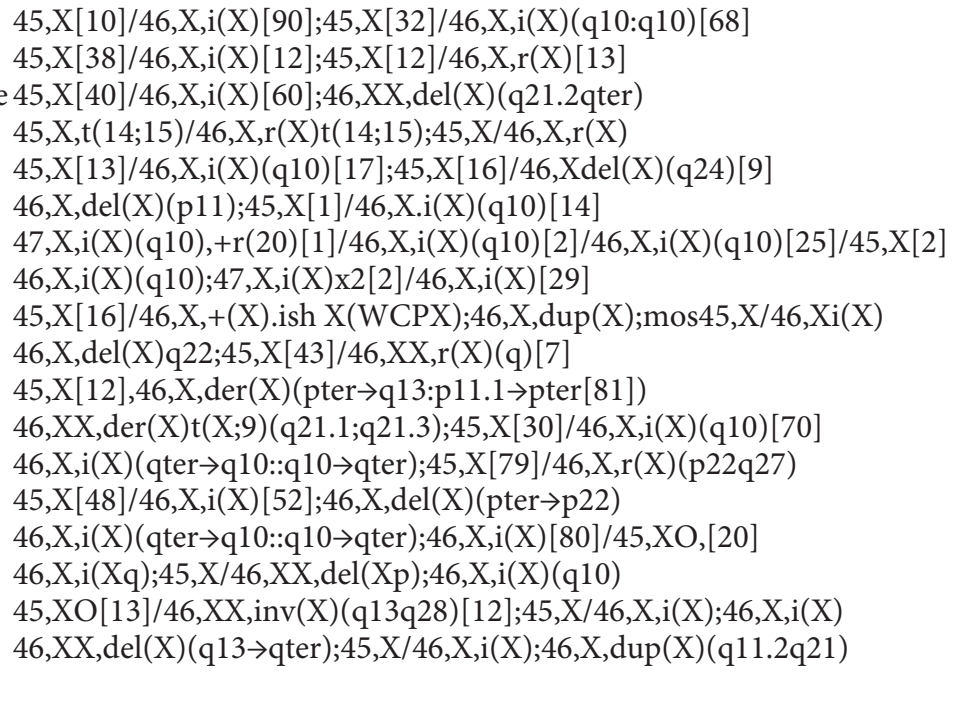 & $\begin{array}{r}47 \\
2 \\
2 \\
2 \\
2 \\
2 \\
2 \\
1 \\
2 \\
3 \\
2 \\
1 \\
2 \\
2 \\
2 \\
2 \\
3 \\
6 \\
9\end{array}$ & 43.9 \\
\hline Monosomy X & $\begin{array}{l}45, \mathrm{X} 0 \\
45, \mathrm{XO}, \mathrm{inv}[9]\end{array}$ & $\begin{array}{r}44 \\
1\end{array}$ & 42.1 \\
\hline Mosaic karyotype & $\begin{array}{l}45, \mathrm{X}[15] / 46, \mathrm{XX}[35] ; 45, \mathrm{X}[25] / 46, \mathrm{XX}[75] ; 45, \mathrm{X}[22] / 46, \mathrm{XX}[28] \\
45, \mathrm{X}[11] / 46, \mathrm{XX}[89] ; 45, \mathrm{X} / 47, \mathrm{XXX} 445, \mathrm{X}[23] / 46, \mathrm{XX}[7] \\
45, \mathrm{X}[4] / 46, \mathrm{XX}[46] ; 45, \mathrm{X}[121] / 47, \mathrm{XXX}[7] ; 45, \mathrm{X}[14] / 46, \mathrm{XX}[36] \\
45, \mathrm{X}[44] / 47, \mathrm{XXX}[6] ; 45, \mathrm{X}[48] / 46, \mathrm{X},+\operatorname{mar}[2]\end{array}$ & $\begin{array}{r}11 \\
3 \\
3 \\
3 \\
2\end{array}$ & 10.3 \\
\hline $\begin{array}{l}\text { Includes Y chromosome or the } \\
\text { fragments of Y chromosome }\end{array}$ & $\begin{array}{l}\text { 45,X[6]/46,XY[8];45,X[5]/46,XY[20];45,X[8]/46,X,del(Y)(q12)[12] } \\
46, \mathrm{X}, \operatorname{del}(\mathrm{Y})(\mathrm{q} 12)[12]\end{array}$ & $\begin{array}{l}4 \\
3 \\
1\end{array}$ & 3.7 \\
\hline
\end{tabular}

clinic. The most common karyotype was X structural abnormality (43.9\%). In the literature, the most common karyotype was monosomy $\mathrm{X}$ in TS individuals; however, in a previous study, frequency of $\mathrm{X}$ structural abnormality was shown to be as high as monosomy X [Lippe, 1991]. Prevalence of renal and cardiac anomalies were 17.9 and $25.8 \%$, respectively, renal findings being less prevalent than in the literature.

The diagnosis may be established at various ages [Stochholm et al., 2006]. Prenatally, fetal ultrasonographic findings such as increased nuchal translucency, cystic hygroma, left-sided obstructive cardiac anomalies (especially coarctation of the aorta) are highly suggestive of TS. Postnatally, karyotype analysis may be undertaken in the presence of clinical features such as fetal hydrops or cystic hygroma, unexplained short stature, delayed puberty, obstructive left-sided cardiac abnormality (including bicuspid aortic valve, aortic coarctation, aortic stenosis, hypoplastic left heart syndrome, or mitral valve abnormalities) or renal anomaly (such as renal hypoplasia/aplasia and horseshoe kidney) [Shankar and Backeljauw, 2018]. In our study, there were only 4 prenatally diagnosed patients (3.7\%) and additionally 12 patients (11.2\%) with hand and foot lymphedema who were diagnosed in the postnatal period.

Short stature, pubertal delay/ovarian insufficiency are the most common complaints [Shankar and Backeljauw, 2018]. In a case series, $4 \%$ of the girls referred for genetic evaluation of isolated short stature, regardless of familial background height, were diagnosed with TS [Sävendahl and Davenport, 2000]. More than $30 \%$ of the patients who had amenorrhea or distinctive phenotypic features had TS. Karyotyping is indicated for girls with unexplained short stature (more than 2 SD below the mean height for age) [Morgan, 2007]. In our study at the first admission, $65(60.7 \%)$ patients had short stature, $3(2.8 \%)$ patients had primary ovarian failure, and $16(15 \%)$ patients had both short stature and primary amenorrhea. 
Two (1.9\%) patients were referred for trigonocephaly. The ratio of patients admitted due to primary ovarian failure was lower than in the literature, most probably because the patients included in the study were younger than 18 years.

A standard 30-cell karyotype is recommended by the American College of Medical Genetics and can detect at least $10 \%$ mosaicism with $95 \%$ confidence [Pinsker, 2012]. In a recent study, the classic karyotype 45 , $X$ was found in $40-60 \%$ of the patients; the remaining patients had either mosaic karyotype (i.e., 45,X/46,XX or $45, \mathrm{X} / 47, \mathrm{XXX})$, or X chromosome structural abnormalities (e.g., $i(X q), i(X p)$, segmental deletions or duplications) or presence of the entire $\mathrm{Y}$ chromosome or its fragments. Another study shows that X structural abnormality was detected in $43.5 \%$ of the patients [Cui et al., 2018]. In our study, 45,X was detected in $44(42.1 \%)$ patients, mosaic karyotype in 11 (11.3\%) patients, X structural abnormality in 47 (43.9\%) patients, and Y chromosome or its fragments in $4(3.7 \%)$ patients, which was consistent with the literature. Y-chromosomal material may be present in 5\% of individuals with TS, and an additional 3\% of individuals may have a marker chromosome (a chromosome fragment of X or Y origin) [Pinsker, 2012]. In our study, Y chromosome material was detected in 4 patients, and marker chromosome was detected in 1 patient. Identification of Y chromosome material in females with TS is important because of the risk of gonadoblastoma [Saenger, 1996]. In case of virilization or marker chromosome detection by routine cytogenetic methods, other genetic tools including FISH should be applied to detect Y chromosome mosaicism [Ranke and Saenger, 2001]. Some studies showed that the risk of gonadoblastoma in patients with $\mathrm{Y}$ chromosome material has been estimated as more than $30 \%$, although some other studies suggest a risk of only 7-10\% [Morgan, 2007]. In our study, because of high risk of gonadoblastoma, gonadectomy was performed in 4 patients in whom $\mathrm{Y}$ chromosome and fragments were detected in karyotype analysis.

On physical examination, individuals with TS exhibit a great variety of somatic features. Clinical manifestations vary and may be subtle but most common findings are short stature, webbed neck, broad chest with widely spaced nipples, cubitus valgus, and short metacarpal bones [Morgan, 2007]. Approximately 50\% have cubitus valgus, $40 \%$ have a low hairline and short-webbed neck, $35 \%$ of the patients have short metacarpal bones, and $5 \%$ have widely-spaced nipples [Los and Rosenfeld, 2019]. When the patients were divided into 4 groups according to their karyotypes, the most common finding in all
Table 3. Height percentiles $(\mathrm{P})$ and main reasons of admission

\begin{tabular}{lc}
\hline Main reasons of admission & $\begin{array}{l}N=107 \\
\text { (frequency) }\end{array}$ \\
\hline Short stature & $65 / 107(60.7 \%)$ \\
<3rd P & $88 / 107(82.2 \%)$ \\
3rd P & $3 / 107(2.8 \%)$ \\
3rd-10th P & $6 / 107(5.6 \%)$ \\
10th P & $1 / 107(0.9 \%)$ \\
10th-25th P & $1 / 107(0.9 \%)$ \\
25th P & $1 / 107(0.9 \%)$ \\
25th-50th P & $2 / 107(1.9 \%)$ \\
50th P & $1 / 107(0.9 \%)$ \\
90th-97th P & $1 / 107(0.9 \%)$ \\
No data available & $4 / 107(3.7 \%)$ \\
Short stature and primary amenorrhea & $20 / 107(18.7 \%)$ \\
Postnatal findings (hand/foot lymphedema) & $12 / 107(11.2 \%)$ \\
Prenatal findings & $4 / 107(3.7 \%)$ \\
Premature ovarian insufficiency & $3 / 107(2.8 \%)$ \\
Trigonocephaly & $2 / 107(1.9 \%)$ \\
No data available & $1 / 107(0.9 \%)$ \\
\hline
\end{tabular}

groups was short stature. Deficit in height is caused by haploinsufficiency of the short-stature homeobox-containing gene (SHOX) located within the Xp terminal, in the pseudoautosomal region of the $\mathrm{X}$ chromosome [Bondy, 2007]. This affects almost all girls with TS and causes short stature more than $20 \mathrm{~cm}$ from the target height.

The most serious, life-threatening consequences of $\mathrm{X}$ chromosome haploinsufficiency are related to the cardiovascular system [Bondy, 2007]. Major defects in fetal heart and aortic development are associated with miscarriage in most 45, X karyotype fetuses [Bondy, 2007]. Congenital heart disease occurs in about $75 \%$ of fetuses and $25-45 \%$ of live-born girls with TS. Adults with TS have a 4- to 5-fold increased premature mortality rate, often attributed to complications of congenital heart disease and premature coronary artery disease [Bondy et al., 2009]. According to the guidelines, at the time of diagnosis, all individuals should have a cardiac evaluation, regardless of age, including a complete physical examination and echocardiogram [Saenger et al., 2001;Gravholt et al., 2017]. Patients with no findings on prenatal echocardiography should be examined postpartum to ensure that there is no bicuspid aortic valve or coarctation of the aorta. Because of an increased risk of high blood pressure, this should be monitored at least once a year [Saenger et al., 2001;Gravholt et al., 2017]. If a baseline echocardiogram does not adequately rule out congenital structural abnormalities, then cardiac MRI can be used [Pinsker, 2012]. In TS, the prevalence of congenital heart malfor- 
mations ranges from 17 to $45 \%$ [Sybert, 1998]. Although the most common cardiac findings are bicuspid aorta and aortic coarctation, aortic dilatation is the most common cause of mortality. There are important differences among studies on the type and frequency of cardiovascular anomalies associated with TS. In previous studies, the prevalence of cardiovascular malformations was significantly higher in the 45,X karyotype. However, the association between the cardiovascular malformations and karyotypes differed among the several studies. While one study showed that aortic coarctation was more prevalent than in mosaic monosomy $\mathrm{X}$ and there were no cardiac abnormalities in structural X chromosome abnormality, the other study demonstrated bicuspid aortic valve and aortic valve disease were more common in the patients with X structural abnormalities [Gøtzsche et al., 1994; Mazzanti and Cacciari, 1998]. In our study, cardiovascular abnormality was found in $25.8 \%$ of the patients, and there was no significant difference in the frequency of cardiac anomalies among the 4 different karyotype groups. Interestingly, the most common findings were left ventricular outflow tract and aortic arch pathologies, which were found in only 9 patients $(8.4 \%)$, and 1 patient died because of Eisenmenger syndrome due to PDA. Unfortunately, patients could not be evaluated retrospectively in terms of hypertension since the records of blood pressure measurements were not available.

Renal malformations occur in approximately $33-66 \%$ of the patients with TS [Flynn et al., 1996]. Although most structural anomalies do not initially present with symptoms, early diagnosis is important because of the risk of hypertension, urinary tract infection, and hydronephrosis. As a result, renal ultrasonography should be performed at the time of diagnosis in all girls with TS to allow the diagnosis of clinically significant abnormalities, especially urinary system malformations [Carvalho et al., 2010]. If abnormalities are detected, further assessment should be done, and appropriate treatment should be applied. Individuals with renal anomalies should have renal ultrasonography and urine culture every 3-5 years [Saenger et al., 2001]. Although horseshoe kidney is the most common anomaly, different rotational abnormalities, duplication of collecting system, and other collecting system malformations such as hydronephrosis due to stenosis of different sites of the ureter are also observed. In line with the existing literature, renal malformation was detected in 15 of 69 (17.9\%) patients who underwent renal ultrasonography in the present study. The relationship of the renal abnormalities to chromosomal karyotype were different in several studies. While several previ- ous studies showed that a significantly greater association of renal malformation was found with monosomy $45, \mathrm{X}$ than with mosaicism, this relationship in other studies was not reported, as in our study [Lippe et al., 1988; Flynn et al., 1996; Bilge et al., 2000; Chang et al., 2000]. The frequency of renal anomaly was found to be lower compared to the literature. One reason for this may be the inadequate screening of patients in terms of renal anomaly since the availability of ultrasonography was less in 2000 than in the present years. Another reason may be that the patients were more likely lost to follow-up in this period, and the data regarding ultrasonographic evaluation were missing. Nevertheless, the frequency of renal anomalies was still $20.6 \%$ between the years 2008 and 2018, when 71 patients were under regular follow-up whose renal sonography reports were available. And finally, renal ultrasonography could possibly underestimate kidney anomalies and further evaluation might yield higher. Renal sonography has been advocated as a potential replacement for intravenous urography in initial screening for renal malformations in patients with TS. A recent study revealed that renal sonography might miss horseshoe kidney and duplex kidney in a significant number of cases, possibly because of an overlying bowel [Chang et al., 2000]. Abnormalities of the renal axis and rotation are also better shown by intravenous urography [Chang et al., 2000]. Also it is shown that it can be difficult for renal sonography to detect nonobstructed duplex kidneys [Sävendahl and Davenport, 2000]. Based on this, the lower prevalence of renal findings in the present study may be due to the evaluation by ultrasonography only.

In conclusion, karyotype analysis should be carried out in a female patient with short stature even in the absence of consistent phenotypic features of TS. Echocardiagraphy should be performed as soon as the diagnosis is established since cardiac anomalies represent the most common anomaly in TS and may well be associated with increased mortality. Additionally, urinary system evaluation should be undertaken since renal anomalies and urinary tract infections have an increased frequency in TS patients and referral to a subspecialist should be considered even if the renal ultrasonography is normal.

\section{Statement of Ethics}

The study protocol was approved by the Hacettepe University Ethics Committee (GO 15-530/25). Written informed consent was obtained from the parents. This article does not contain any studies with human participants or animals performed by any of the authors. 


\section{Conflict of Interest Statement}

The authors declare that they have no conflicts of interest.

\section{Funding Sources}

The study was supported by Hacettepe University Research Fund with grant No. TAY-2015-7335.

\section{Author Contributions}

Conception (constructing an idea or hypothesis for research and/or manuscript): A.A., P.S.-K.

Design (planning methodology to reach the conclusion): G.U., P.S.-K., and K.B.
Supervision (organising and supervising the course of the project or the article and taking the responsibility): G.U., P.S.-K.

Funding sources (providing personnel, environmental and financial support and tools, and instruments that are vital for the project): G.U., P.S.-K., and K.B.

Materials (biological materials, reagents and referred patients): A.A., P.S.-K.

Data collection/processing (responsible for performing experiments, patient follow-up, data management and reporting): A.A., İ.E., and P.S.-K.

Analysis/interpretation (responsible for logical interpretation and presentation of the results): A.A., P.S.-K.

Literature review: A.A., P.S.-K.

Writing (responsible for manuscript construction): A.A., G.U., and P.S.-K.

Critical review (complete article review before submission): A.A., G.U., and P.S.-K.

\section{References}

Bilge I, Kayserili H, Emre S, Nayir A, Sirin A, Tukel T, et al. Frequency of renal malformations in Turner syndrome: analysis of 82 Turkish children. Pediatr Nephrol. 2000; 14(12):1111-4.

Bondy CA; Turner Syndrome Study Group . Care of girls and women with Turner syndrome: a guideline of the Turner Syndrome Study Group. J Clin Endocrinol Metab. 2007;92(1): $10-25$.

Bondy C, Rosing D, Reindollar R. Cardiovascular risks of pregnancy in women with Turner syndrome. Fertil Steril. 2009;91(5):e31-32.

Carvalho AB, Guerra Júnior G, Baptista MT, de Faria AP, Marini SH, Guerra AT. Cardiovascular and renal anomalies in Turner syndrome. Rev Assoc Med Bras (1992). 2010; 56(6):655-9.

Chang P, Tsau YK, Tsai WY, Tsai WS, Hou JW, Hsiao PH, et al. Renal malformations in children with Turner's syndrome. J Formos Med Assoc. 2000;99(10):796-8.

Cui X, Cui Y, Shi L, Luan J, Zhou X, Han J. A basic understanding of Turner syndrome: Incidence, complications, diagnosis, and treatment. Intractable Rare Dis Res. 2018;7(4): 223-8.

Flynn MT, Ekstrom L, De Arce M, Costigan C, Hoey HM. Prevalence of renal malformation in Turner syndrome. Pediatr Nephrol. 1996; 10(4):498-500.
Ford C, Jones K, Polani P, De Almeida J, Briggs J. A sex-chromosome anomaly in a case of gonadal dysgenesis (Turner's syndrome). Lancet. 1959;1(7075):711-3.

Gøtzsche C, Krag-Olsen B, Nielsen J, Sørensen K, Kristensen BO. Prevalence of cardiovascular malformations and association with karyotypes in Turner's syndrome. Arch Dis Child. 1994;71(5):433-6.

Gravholt $\mathrm{CH}$, Andersen NH, Conway GS, Dekkers OM, Geffner ME, Klein KO, et al. Clinical practice guidelines for the care of girls and women with Turner syndrome: proceedings from the 2016 Cincinnati International Turner Syndrome Meeting. Eur J Endocrinol. 2017;177(3):G1-G70.

Lippe B. Turner syndrome. Endocrinol Metab Clin North Am. 1991;20(1):121-52.

Lippe B, Geffner ME, Dietrich RB, Boechat MI, Kangarloo H. Renal malformations in patients with Turner syndrome: imaging in 141 patients. Pediatrics. 1988;82(6):852-6.

Los E, Rosenfeld RG. Growth and growth hormone in Turner syndrome: Looking back, looking ahead. Am J Med Genet C Semin Med Genet. 2019;181(1):86-90.

Mazzanti L, Cacciari E. Congenital heart disease in patients with Turner's syndrome. Italian Study Group for Turner Syndrome (ISGTS). J Pediatr. 1998;133(5):688-92.

Morgan T. Turner syndrome: diagnosis and management. Am Fam Physician. 2007;76(3): 405-10.
Pinsker JE. Clinical review: Turner syndrome: updating the paradigm of clinical care. J Clin Endocrinol Metab. 2012;97(6):E994-E1003.

Ranke MB, Saenger P. Turner's syndrome. Lancet. 2001;358(9278):309-14.

Saenger P. Turner's syndrome. N Engl J Med. 1996;335(23):1749-54.

Saenger P, Wikland KA, Conway GS, Davenport $\mathrm{M}$, Gravholt $\mathrm{CH}$, Hintz R, et al. Recommendations for the diagnosis and management of Turner syndrome. J Clin Endocrinol Metab. 2001;86(7):3061-9.

Sävendahl L, Davenport ML. Delayed diagnoses of Turner's syndrome: proposed guidelines for change. J Pediatr. 2000;137(4):455-9.

Shankar RK, Backeljauw PF. Current best practice in the management of Turner syndrome. Ther Adv Endocrinol Metab. 2018;9(1):3340.

Stochholm K, Juul S, Juel K, Naeraa RW, Gravholt $\mathrm{CH}$. Prevalence, incidence, diagnostic delay, and mortality in Turner syndrome. J Clin Endocrinol Metab. 2006;91(10):3897-902.

Sybert VP. Cardiovascular malformations and complications in Turner syndrome. Pediatrics. 1998;101(1):e11.

Turner HH. A Syndrome of Infantilism, Congenital Webbed Neck, and Cubitus Valgus1. Endocrinology. 1938;23(5):566-74.

Wolff DJ, Van Dyke DL, Powell CM. Laboratory guideline for Turner syndrome. Genet Med. 2010;12(1):52-5. 